\title{
Postnatal Brain Growth Assessed by Sequential Cranial Ultrasonography in Infants Born <30 Weeks' Gestational Age
}

\author{
(D) R. Cuzzilla, DA.J. Spittle, (D).J. Lee, (D) S. Rogerson, (D)F.M. Cowan, (D) L.W. Doyle, and (D).L.Y. Cheong
}

\begin{abstract}
BACKGROUND AND PURPOSE: Brain growth in the early postnatal period following preterm birth has not been well described. This study of infants born at $<30$ weeks' gestational age and without major brain injury aimed to accomplish the following: 1) assess the reproducibility of linear measures made from cranial ultrasonography, 2) evaluate brain growth using sequential cranial ultrasonography linear measures from birth to term-equivalent age, and 3) explore perinatal predictors of postnatal brain growth.
\end{abstract}

MATERIALS AND METHODS: Participants comprised 144 infants born at $<30$ weeks' gestational age at a single center between January 2011 and December 2013. Infants with major brain injury seen on cranial ultrasonography or congenital or chromosomal abnormalities were excluded. Brain tissue and fluid spaces were measured from cranial ultrasonography performed as part of routine clinical care. Brain growth was assessed in 3 time intervals: $<7,7-27$, and $>27$ days' postnatal age. Data were analyzed using intraclass correlation coefficients and mixed-effects regression.

RESULTS: A total of 429 scans were assessed for 144 infants. Several linear measures showed excellent reproducibility. All measures of brain tissue increased with postnatal age, except for the biparietal diameter, which decreased within the first postnatal week and increased thereafter. Gestational age of $\geq 28$ weeks at birth was associated with slower growth of the biparietal diameter and ventricular width compared with gestational age of $<28$ weeks. Postnatal corticosteroid administration was associated with slower growth of the corpus callosum length, transcerebellar diameter, and vermis height. Sepsis and necrotizing enterocolitis were associated with slower growth of the transcerebellar diameter.

CONCLUSIONS: Postnatal brain growth in infants born at $<30$ weeks' gestational age can be evaluated using sequential linear measures made from routine cranial ultrasonography and is associated with perinatal predictors of long-term development.

ABBREVIATIONS: $\mathrm{AHW}=$ anterior horn width; $\mathrm{BPD}=$ biparietal diameter; $\mathrm{BW}=$ birth weight; $\mathrm{CCL}=$ corpus callosum length; $\mathrm{cUS}=$ cranial ultrasonography; $\mathrm{GA}=$ gestational age; NEC = necrotizing enterocolitis; $\mathrm{PMA}=$ postmenstrual age; PNA = postnatal age; TEA = term-equivalent age; TCD = transcerebellar diameter

$\mathbf{P}$ reterm infants are at risk of long-term neurodevelopmental impairment related to perinatal brain injury and altered brain maturation. ${ }^{1,2}$ The optimal technique and timing of neuroimaging for identifying high-risk infants is under debate. ${ }^{3}$ While early and sequential cranial ultrasonography (cUS) can be reliably used to detect major brain injury, it is less sensitive than MR imaging

Received October 26, 2017; accepted after revision March 5, 2018.

From the Victorian Infant Brain Studies research group (R.C., A.J.S., K.J.L., L.W.D., J.L.Y.C.), Murdoch Childrens Research Institute, Melbourne, Australia; Departments of Obstetrics and Gynaecology (R.C., S.R., LW.D., J.L.Y.C.), Paediatrics (K.J.L., L.W.D.), and Physiotherapy (A.J.S.), University of Melbourne, Melbourne, Australia; Neonatal Services (R.C., A.J.S., S.R., LW.D., J.L.Y.C.), The Royal Women's Hospital, Melbourne, Australia; and Department of Paediatrics (F.M.C.), Imperial College, London, UK. This study was funded by grants from the National Health and Medical Research Council (project grant 1024516; Career Development Fellowship 1108714; Centre for Clinical Research Excellence 546519; Centre for Research Excellence 1060733, and Senior Research Fellowship 628371). The Murdoch Childrens Research Institute is supported by the Operational Infrastructure Support Program of the Victorian Government. for the more prevalent, diffuse white matter injury associated with preterm birth. ${ }^{1,4,5}$ Nonetheless, cUS remains the most widely used neuroimaging technique for preterm infants because it is readily available, easily repeatable, and sensitive enough for detecting most major pathology.

In the absence of overt brain injury and where MR imaging is not accessible, there is a need to improve the prognostic utility of cUS, to better understand why some preterm infants without major brain injury seen on cUS later develop motor and cognitive impairments. ${ }^{1,6}$ Most infants born preterm have at least 1 early and 1 later neonatal cUS scan, affording an opportunity to quan-

\footnotetext{
Please address correspondence to Rocco Cuzzilla, MD, Neonatal Services, The Royal Women's Hospital, 20 Flemington Rd, Parkville 3052 Victoria, Australia; e-mail: rocco.cuzzilla@thewomens.org.au

- Indicates open access to non-subscribers at www.ajnr.org

三 Indicates article with supplemental on-line table.

http://dx.doi.org/10.3174/ajnr.A5679
} 


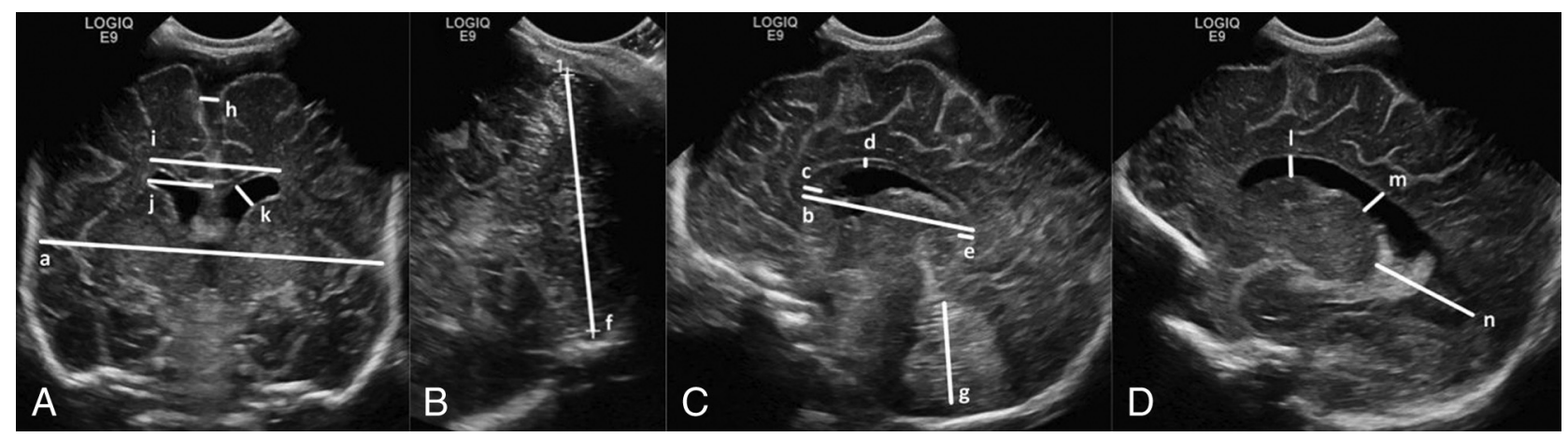

FIG 1. Cranial ultrasonography linear measures: images through the anterior fontanel in the coronal plane at the level of foramina of Monro $(A)$ and the sagittal $(C)$ and parasagittal $(D)$ planes, and an image through the mastoid fontanel in the coronal plane posterior to the fourth ventricle (B). Brain tissue: biparietal diameter (a), corpus callosum length (b), corpus callosum genu width (c), corpus callosum body height (d), corpus callosum splenium width (e), transcerebellar diameter ( $\mathrm{f}$, and vermis height (g). Fluid spaces: interhemispheric distance (h), ventricular width (i), ventricular index $(\mathrm{j})$, anterior horn width $(\mathrm{k})$, anterior horn height $(\mathrm{l})$, ventricular midbody width $(\mathrm{m})$, and thalamo-occipital distance $(\mathrm{n})$.

tify early brain growth as a potential marker of long-term development that has not been fully exploited. ${ }^{7}$

Linear measures of brain tissue and fluid spaces made from neonatal cUS have been associated with neurodevelopmental outcomes in preterm children. ${ }^{8,9}$ However, only 2 studies have evaluated early postnatal brain growth using sequential cUS. ${ }^{9,10}$ In a study of 140 infants born at $<29$ weeks' gestational age (GA), Roelants et $\mathrm{al}^{10}$ reported normative data for the growth of the corpus callosum length (CCL) and corpus callosum-fastigium length with respect to postmenstrual age (PMA), but they did not relate brain growth with postnatal age (PNA). The study of 61 very-low-birth-weight infants by Anderson et $\mathrm{al}^{9}$ found that slower growth of the CCL between 2 and 6 weeks' PNA was predictive of motor delay and cerebral palsy at 2 years; however, this study included infants with major brain injury.

To explore further the usefulness of cUS in assessing brain growth in preterm infants without major brain injury, we aimed to achieve the following: 1) assess the reproducibility of linear measures of brain tissue and fluid spaces made from cUS, 2) evaluate brain growth with respect to PNA using sequential cUS linear measures from birth to term-equivalent age (TEA), and 3) explore the associations between perinatal variables and postnatal brain growth measured by cUS.

\section{MATERIALS AND METHODS \\ Study Participants}

One hundred forty-nine infants born at $<30$ weeks' GA at The Royal Women's Hospital, Melbourne, Australia, between January 2011 and December 2013, were recruited into a prospective longitudinal study of neuroimaging, neurobehavior, and long-term development. ${ }^{11}$ Infants with congenital or chromosomal anomalies known to affect neurodevelopment were excluded. For the current study, 5 infants with major preterm brain injury detected on cUS were also excluded, including infants with grades III or IV intraventricular hemorrhage, posthemorrhagic ventricular dilation, and cystic periventricular leukomalacia, leaving 144 infants for analysis. ${ }^{12,13}$ The study received institutional approval from the Human Research Ethics Committee of the hospital, and written informed consent was obtained from parents of all participants.

\section{Cranial Ultrasonography}

cUS was performed as part of routine clinical care using a Logiq 9 Ultrasound System and an 8-MHz broadband curvilinear transducer (GE Healthcare, Milwaukee, Wisconsin). Standard images were acquired through the anterior fontanel ( 5 images in different coronal planes, an image in the midsagittal plane, and 2 images in different parasagittal planes both on the left and right) and the mastoid fontanel (1 image in the coronal plane). As per local protocol for the surveillance of preterm brain injury, infants born at $<30$ weeks' GA were scanned on, or around, days 7, 28, and 60 PNA. Infants born at $<28$ weeks' GA were also scanned on, or around, day 1 PNA. Additional scans were performed depending on clinical need. The current study included all neonatal scans performed from birth to TEA ( $<42$ weeks' PMA).

Nineteen linear measures of brain tissue and fluid spaces were explored on the basis of potential clinical importance, ease of recognition of anatomic landmarks on standard imaging planes, and evaluation of their reproducibility (Fig 1). A neonatologist (R.C.) blinded to the clinical course of study participants and with 4 years' experience in performing cUS obtained measurements using electronic calipers on stored digital images (Synapse; Fujifilm Medical Company, Minato-Ku, Japan). Thirty scans $(7 \%)$ were randomly selected to assess the reproducibility of the linear measures. Measurements were made by the same observer (R.C.) twice, at least 1 month apart, and once by another observer (S.R.) with 20 years' experience in performing cUS.

\section{Perinatal Predictors of Long-Term Neurodevelopment}

Perinatal variables were chosen a priori on the basis of their known associations with brain injury and long-term neurodevelopmental outcomes following preterm birth. ${ }^{14}$ These included GA at birth (determined by first-trimester ultrasonography when available or by menstrual history), birth weight SD score (BW $z$ score), sex, multiple gestations, chorioamnionitis (confirmed by placental histology), antenatal corticosteroids (any number of doses of betamethasone) and magnesium sulfate (for maternal or fetal indications), bronchopulmonary dysplasia (defined by oxygen requirement at 36 weeks' PMA), postnatal corticosteroids, confirmed sepsis (blood or CSF culture-positive and the use of antibiotics for $\geq 5$ days) and/or necro- 
tizing enterocolitis (NEC; defined by stage II or higher modified Bell criteria), and low-grade intraventricular hemorrhage (grades I or II) seen on cUS (defined by Papile classification). ${ }^{13,15}$

\section{Data Analysis}

Data were analyzed using STATA, Version 13.1 (StataCorp, College Station, Texas). Intra- and interobserver agreement was assessed by the intraclass correlation coefficient. Linear measures with both intra- and interobserver intraclass correlation coeffi-

\section{Table 1: Infant characteristics}

\begin{tabular}{|c|c|}
\hline Perinatal Variable & $\begin{array}{c}\text { Summary } \\
(N=144 \text { Infants })\end{array}$ \\
\hline Gestational age (mean) (SD) (wk) & $27.7(1.5)$ \\
\hline Birth weight (mean) (SD) (g) & $1017(259)$ \\
\hline $\begin{array}{l}\text { Small for gestational age, birth weight }<-2 \\
\text { SDs (No.) (\%) }\end{array}$ & $16(11)$ \\
\hline Female (No.) (\%) & $75(52)$ \\
\hline Multiple gestations (No.) (\%) & $64(44)$ \\
\hline Cesarean delivery (No.) (\%) & $106(74)$ \\
\hline Antenatal corticosteroids (No.) (\%) & $134(93)$ \\
\hline Antenatal magnesium sulfate (No.) (\%) & $103(72)$ \\
\hline Respiratory distress from birth (No.) (\%) & $141(98)$ \\
\hline Surfactant (No.) (\%) & $91(63)$ \\
\hline $\begin{array}{l}\text { Duration of positive pressure ventilation } \\
\text { (median) (25th-75th centile) (days) }\end{array}$ & $19(0-96)$ \\
\hline $\begin{array}{l}\text { Duration of supplemental oxygen (median) } \\
\text { (25th- } 75 \text { th centile) (days) }\end{array}$ & $19(4-56)$ \\
\hline Bronchopulmonary dysplasia ${ }^{a}(\mathrm{No}).(\%)$ & $46(32)$ \\
\hline Postnatal corticosteroids (No.) (\%) & $18(13)$ \\
\hline $\begin{array}{l}\text { Intraventricular hemorrhage, grades I or II } \\
\text { (No.) (\%) }\end{array}$ & $25(17)$ \\
\hline Retinopathy of prematurity (No.) (\%) & $32(22)$ \\
\hline Sepsis confirmed ${ }^{\mathrm{b}}$ (No.) (\%) & $20(14)$ \\
\hline NEC (No.) (\%) & $17(12)$ \\
\hline Sepsis confirmed and/or NEC (No.) (\%) & $31(22)$ \\
\hline Survived to discharge home (No.) (\%) & $139(97)$ \\
\hline
\end{tabular}

Table 2: Reproducibility of cranial ultrasonography linear measures

\begin{tabular}{|c|c|c|c|c|}
\hline \multirow[b]{2}{*}{ Linear Measure } & \multicolumn{2}{|c|}{ Intraobserver } & \multicolumn{2}{|c|}{ Interobserver } \\
\hline & ICC & $95 \% \mathrm{Cl}$ & ICC & $95 \% \mathrm{Cl}$ \\
\hline \multicolumn{5}{|l|}{ Brain tissue } \\
\hline Biparietal diameter & 0.98 & $0.95-0.99$ & 0.97 & $0.94-0.99$ \\
\hline Corpus callosum length & 0.99 & $0.97-0.99$ & 0.98 & $0.95-0.99$ \\
\hline Corpus callosum genu width & 0.78 & $0.53-0.90$ & 0.38 & $-0.04-0.69$ \\
\hline Corpus callosum body height & 0.74 & $0.52-0.87$ & 0.58 & $0.27-0.78$ \\
\hline Corpus callosum splenium width & 0.80 & $0.56-0.92$ & 0.21 & $-0.22-0.58$ \\
\hline Transcerebellar diameter & 0.99 & $0.98-0.99$ & 0.98 & $0.96-0.99$ \\
\hline Vermis height & 0.91 & $0.82-0.96$ & 0.81 & $0.62-0.91$ \\
\hline \multicolumn{5}{|l|}{ Fluid spaces } \\
\hline Interhemispheric distance & 0.98 & $0.96-0.99$ & 0.98 & $0.95-0.99$ \\
\hline Anterior horn width, left & 0.94 & $0.87-0.97$ & 0.91 & $0.81-0.96$ \\
\hline Anterior horn width, right & 0.96 & $0.90-0.98$ & 0.95 & $0.89-0.98$ \\
\hline Ventricular index, left & 0.85 & $0.70-0.93$ & 0.85 & $0.69-0.93$ \\
\hline Ventricular index, right & 0.63 & $0.32-0.82$ & 0.59 & $0.26-0.80$ \\
\hline Ventricular width & 0.87 & $0.72-0.94$ & 0.89 & $0.76-0.95$ \\
\hline Anterior horn height, left & 0.86 & $0.72-0.94$ & 0.76 & $0.53-0.88$ \\
\hline Anterior horn height, right & 0.92 & $0.82-0.96$ & 0.78 & $0.55-0.90$ \\
\hline Ventricular midbody height, left & 0.73 & $0.49-0.87$ & 0.47 & $0.11-0.72$ \\
\hline Ventricular midbody height, right & 0.81 & $0.61-0.91$ & 0.52 & $0.18-0.75$ \\
\hline Thalamo-occipital distance, left & 0.93 & $0.81-0.97$ & 0.80 & $0.52-0.93$ \\
\hline Thalamo-occipital distance, right & 0.92 & $0.80-0.97$ & 0.62 & $0.22-0.84$ \\
\hline
\end{tabular}

Note:-ICC indicates intraclass correlation coefficient. cients of $>0.80$ were considered for inclusion in further analyses. Brain growth (or rate of change) with respect to PNA was assessed using mixed-effects linear regression fitted to all the sequential measurements from all individuals, with PNA as the time variable and a random effect for an individual fitted with an unstructured covariance matrix. The model included a random effect to account for multiple measurements for each infant, with a fixed effect of time. First, overall brain growth was assessed from birth to TEA using a single time variable. Brain growth was then assessed within 3 time intervals to reflect the timing of our routine cUS by fitting separate effects of time in the periods $<7,7-27$, and $>27$ days' PNA. Analyses were repeated with adjustment for GA, BW $z$ score, and sex. Associations between perinatal variables and brain growth with respect to PNA (fitting a single effect of time from birth to TEA) were explored separately by including an interaction between the perinatal variable and PNA in the mixed-effects linear regression model. Continuous variables were dichotomized for this analysis: GA group ( $<28$ weeks or $28-29$ weeks) and BW $z$ score group $(<-2$ or $\geq-2$ SDs from the mean). Analyses were repeated with adjustment for GA, BW $z$ score, and sex, with the exception that GA and the BW $z$ score were not adjusted for when exploring the effect of the GA group and BW $z$ score group, respectively. Measurements of the left and right anterior horn widths (AHWs) included the germinal layer hemorrhage when present. Consequently, all analyses involving the AHW were restricted to infants without an ipsilateral intraventricular hemorrhage, to eliminate the influence of the germinal layer hemorrhage on the generalizability of results with respect to rates of change of the AHW with PNA.

\section{RESULTS}

Characteristics of the 144 infants included in the current study are presented in Table 1. In the 144 infants, 429 scans were performed from birth to TEA. The mean number of scans per infant was 3 (range, 1-8). For the 77 infants born at $<28$ weeks' GA, 291 scans were assessed (mean, 3.8; range, 1-8 per infant), and 138 scans for the 67 infants born at $\geq 28$ weeks' GA (mean, 2.1; range, $1-6$ per infant). Almost two-thirds $(n=272$; $63 \%)$ of the scans were performed at $<28$ days' PNA, but most infants had scans up to 33 weeks' PMA.

\section{Intra- and Interobserver Reproducibility}

Intra- and interobserver intraclass correlation coefficients are shown in Table 2. Eight linear measures, 4 of brain tissue (biparietal diameter [BPD], CCL, transcerebellar diameter [TCD], and vermis height) and 4 reflecting fluid spaces (interhemispheric distance, left and right AHWs, and ventricular width), had intraclass correlation coefficients of $>0.8$ both between and within observers and were used to evaluate brain growth. 


\section{Brain Growth with Respect to Postnatal Age}

There was evidence that all linear measures of brain tissue increased with PNA, before and after adjustment for GA, BW $z$ score, and sex, overall and within the 3 time intervals, except for the BPD, which decreased within the first postnatal week (Fig 2 and On-line Table). Faster rates of growth of the BPD, TCD, and vermis height were observed after 27 days' PNA compared with 7-27 days' PNA; however, the rate of growth of the CCL more than halved after 27 days' PNA compared with 7-27 days' PNA (Fig 2 and On-line Table).

Rates of change of linear measures of fluid spaces were variable within the first postnatal week, with little evidence of an association between linear measures and PNA (Fig 2 and Online Table). The interhemispheric distance and ventricular width increased after the first postnatal week, with faster rates of change after 27 days' PNA (1.5 and 2.7 times, respectively) compared with 7-27 days' PNA. Although the rates of change for the AHW appeared to decrease with successive time intervals, there was little statistical evidence of an association between the AHW and PNA, except for the right AHW between 7 and 27 days' PNA.

\section{Associations between Perinatal Variables and Postnatal Brain Growth}

There was strong evidence of associations between many of the perinatal variables and brain growth with respect to PNA, which remained after adjustment for GA, BW $z$ score, and sex (Table 3). Infants born at 28-29 weeks' GA showed slower growth of the BPD and ventricular width than infants born at $<28$ weeks' GA. Postnatal corticosteroid administration was associated with slower growth of the CCL, TCD, and vermis height, and bronchopulmonary dysplasia was associated with slower growth of the CCL and TCD. Infants with a BW $z$ score $<-2$ SDs below the mean showed slower growth of the CCL than infants with $\mathrm{BW} \geq-2 \mathrm{SD}$ below the mean. Sepsis and/or NEC and antenatal corticosteroid administration were associated with slower growth of the TCD.

\section{DISCUSSION}

In this study of early postnatal brain growth in infants born at $<30$ weeks' GA and without major brain injury, several linear measures of brain tissue and fluid spaces were reliably made from routine clinical cUS scans. Most linear measures of brain tissue increased with PNA, but rates of change were more variable for the fluid spaces. Several perinatal variables related to long-term development were associated with postnatal brain growth. Bronchopulmonary dysplasia and postnatal corticosteroid administration were associated with slower growth of the CCL and TCD, and postnatal corticosteroid administration was also associated with slower growth of the vermis height. Sepsis and/or NEC were associated with slower growth of the TCD.

Measurements of brain growth for use in clinical practice should be simple to obtain and reproducible. The cUS linear measures explored in this study had well-defined anatomic landmarks on standard imaging planes obtained during routine clinical care, and several showed excellent intra- and interobserver reproducibility, as also shown by others. ${ }^{8,10,16,17}$
Although cUS affords an opportunity to make sequential measurements from birth, there are limited published data relating to postnatal brain growth in preterm infants. To our knowledge, this study is the first to describe the growth of the BPD in the early postnatal period following preterm birth using sequential cUS. We speculate that the decreasing size of the BPD in the first postnatal week found in the current study may relate to a reduction in brain-water in the immediate postnatal days rather than deformational changes in head shape. ${ }^{18}$ Growth of the BPD between 7 and 27 days was slower $(1.30 \mathrm{~mm} /$ week PNA) than after the first 27 days $(2.17 \mathrm{~mm} /$ week PNA), from which time postnatal growth of the BPD approximates to expected fetal growth $(2.10 \mathrm{~mm} /$ week PMA) as reported from cross-sectional data by Kurmanavicius et al. ${ }^{19}$ Higher GA at birth related to slower growth of the BPD from birth to TEA, in keeping with normative data for fetal growth of the BPD that demonstrates a slowing of growth with increasing PMA. ${ }^{19,20}$ However, infants born at $<30$ weeks' GA have smaller brains at TEA than term-born controls, and most are likely to have slower rates of brain growth immediately after birth than normally expected in utero. ${ }^{20,21}$

In the current study, CCL growth was relatively constant from birth to 27 days' PNA but slowed by half thereafter. Similarly, Anderson et $\mathrm{al}^{9}$ showed that postnatal growth of the CCL in verylow-birth-weight infants approximated fetal growth (1.4-1.89 $\mathrm{mm}$ /week PMA) within the first 2 postnatal weeks but subsequently slowed to approximately half of that expected. ${ }^{22,23}$ Moreover, the current study found that a BW $z$ score of $<-2$ SDs was associated with slower CCL growth from birth to TEA, a finding consistent with that of Roelants et al. ${ }^{10}$

The TCD measured in the fetus, or the neonate in the first postnatal days, is a reliable marker of GA, even with fetal growth restriction, small- and large-for-gestational age fetuses, and multiple gestations (1.25-1.89 mm/week PMA). ${ }^{24-27}$ Cross-sectional preterm MR imaging studies have reported cerebellar size, but our study is the first to report postnatal growth of the TCD in preterm infants using sequential cUS. ${ }^{20,28}$ Similar to fetal growth patterns, TCD growth in the current study progressively increased between time intervals. Unlike the TCD, the vermis height increased with PNA at a relatively constant rate of change from birth to TEA, approximating fetal growth $\left(0.55 \mathrm{~mm} /\right.$ week PMA). ${ }^{29}$

Bronchopulmonary dysplasia and postnatal corticosteroids were associated with slower CCL and TCD growth with PNA, and postnatal corticosteroid administration was also related to slower growth of the vermis height. Tam et $\mathrm{al}^{30}$ reported a similar association between postnatal corticosteroids, a marker of severe bronchopulmonary dysplasia, and impaired cerebellar growth in very preterm infants using serial MR imaging between 32 weeks' PMA and TEA. In another MR imaging study of very preterm infants scanned at TEA and 7 years, Thompson et $\mathrm{al}^{31}$ reported an association between postnatal corticosteroids and delayed maturation of the posterior corpus callosum, a region that develops later in gestation and contributes to corpus callosum length. In the current study, sepsis and/or NEC were related to slower growth of the TCD. Sepsis and/or NEC have been associated with preterm white matter injury at TEA, but their relationship with brain growth and maturation in the early postnatal period remains unclear. ${ }^{32}$ The relationship between antenatal corticoste- 
A. Brain tissue
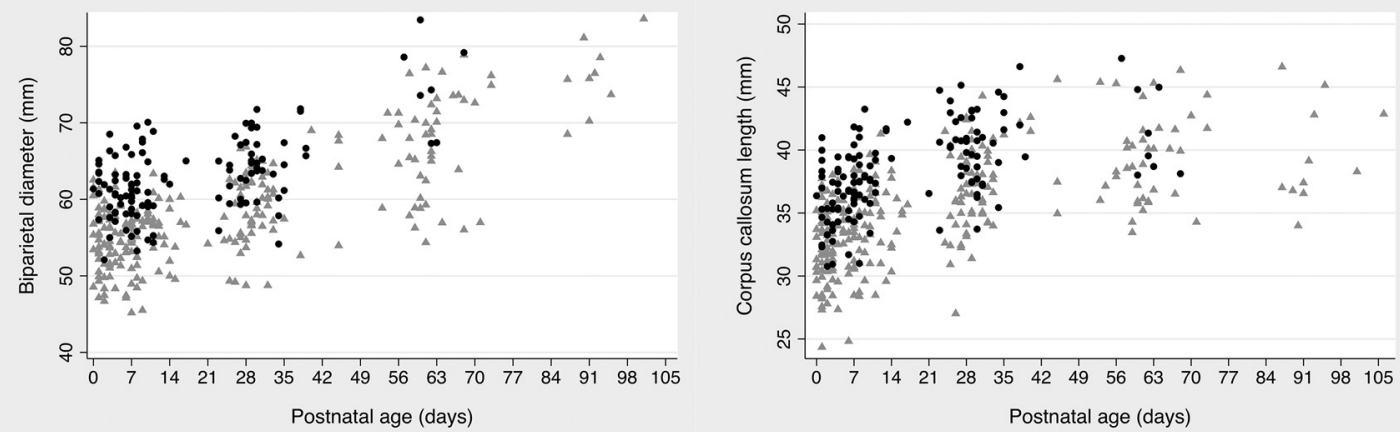

A $\mathrm{GA}<28$ weeks $\bullet \mathrm{GA} 28-29$ weeks

GA $<28$ weeks - GA 28-29 weeks
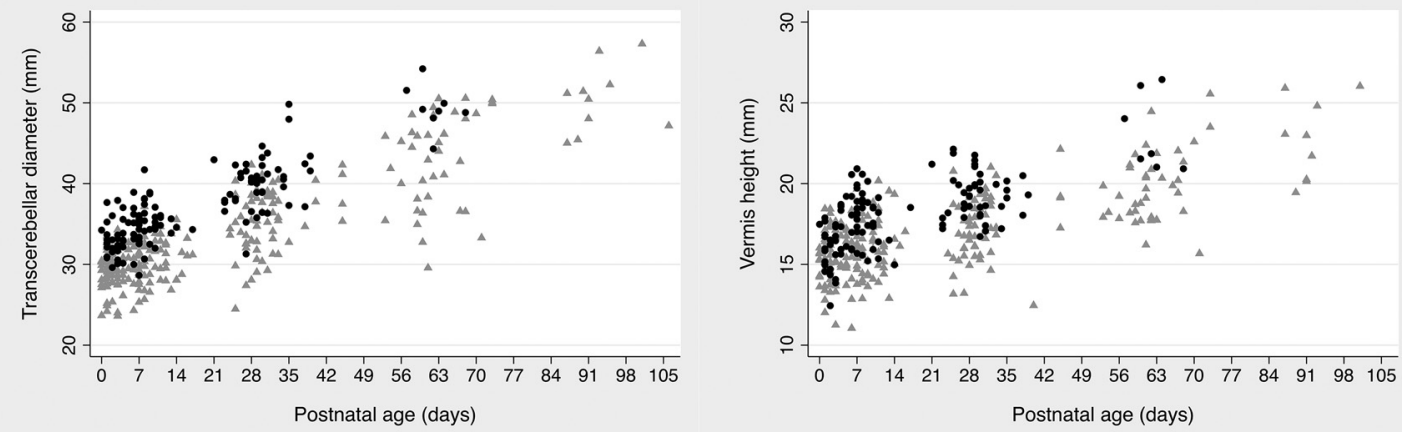

GA $<28$ weeks - GA 28-29 weeks

GA $<28$ weeks $\cdot$ GA 28-29 weeks

B. Fluid spaces
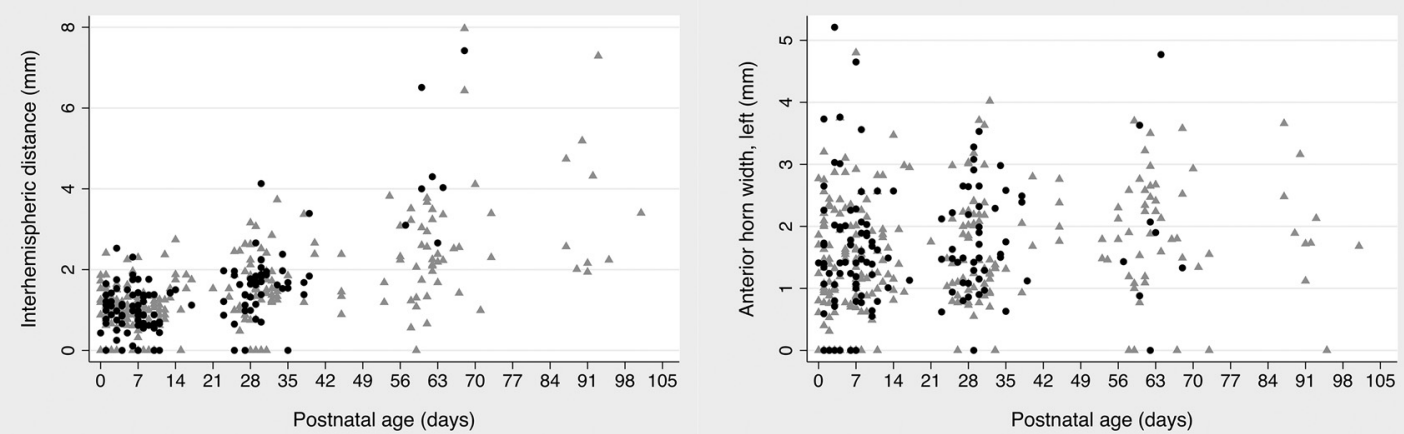

$\triangle \mathrm{GA}<28$ weeks $\bullet \mathrm{GA} 28-29$ weeks

GA $<28$ weeks - GA 28-29 weeks

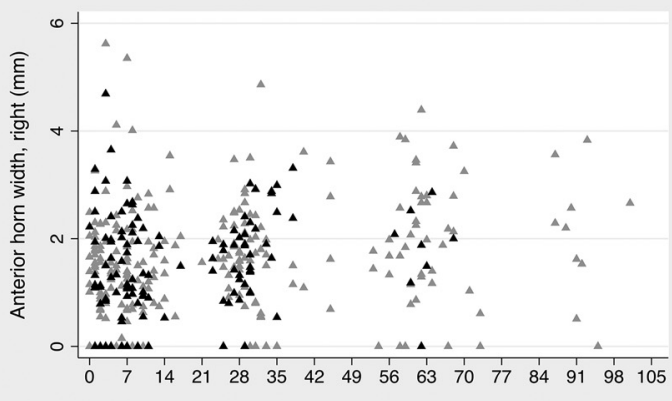

Postnatal age (days)

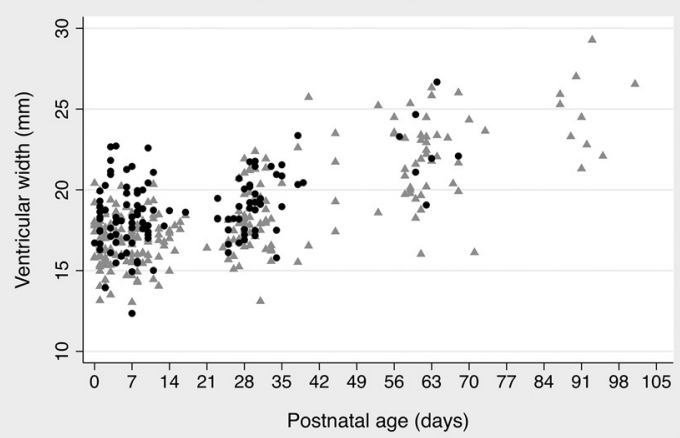

$\mathrm{GA}<28$ weeks $\triangle \mathrm{GA} 28-29$ weeks

GA $<28$ weeks - GA 28-29 weeks

FIG 2. Cranial ultrasonography linear measures with respect to postnatal age. $A$, Brain tissue. $B$, Fluid spaces. 
Table 3: Associations between perinatal variables and postnatal brain growth

\begin{tabular}{|c|c|c|c|}
\hline \multirow[b]{2}{*}{ Perinatal Variable } & \multicolumn{2}{|c|}{$\begin{array}{c}\text { Adjusted }^{\mathrm{a}} \\
\text { Growth (mm/week PNA) }^{\text {(mm }}\end{array}$} & \multirow{2}{*}{$\begin{array}{c}\text { Interaction } \\
\text { Term }^{\mathrm{b}} \\
(P \text { Value })\end{array}$} \\
\hline & $\boldsymbol{\beta}$ & $95 \% \mathrm{Cl}$ & \\
\hline \multicolumn{4}{|l|}{ Biparietal diameter } \\
\hline \multicolumn{4}{|l|}{ GA } \\
\hline$<28$ weeks & 1.88 & $1.71-2.05$ & .002 \\
\hline$\geq 28$ weeks & 1.29 & $0.96-1.62$ & \\
\hline \multicolumn{4}{|l|}{ Corpus callosum length } \\
\hline \multicolumn{4}{|l|}{ BW z score } \\
\hline$\geq-2 \mathrm{SD}$ & 0.91 & $0.84-0.98$ & .045 \\
\hline$<-2 \mathrm{SD}$ & 0.73 & $0.57-0.89$ & \\
\hline \multicolumn{4}{|c|}{ Postnatal corticosteroids } \\
\hline No & 0.92 & $0.85-1.00$ & .046 \\
\hline Yes & 0.77 & $0.63-0.90$ & \\
\hline \multicolumn{4}{|c|}{ Bronchopulmonary dysplasia } \\
\hline No & 0.98 & $0.88-1.07$ & .01 \\
\hline Yes & 0.81 & $0.73-0.89$ & \\
\hline \multicolumn{4}{|l|}{ Transcerebellar diameter } \\
\hline \multicolumn{4}{|l|}{ Antenatal corticosteroids } \\
\hline No & 2.26 & $1.81-2.70$ & .023 \\
\hline Yes & 1.73 & $1.63-1.83$ & \\
\hline \multicolumn{4}{|l|}{ Postnatal corticosteroids } \\
\hline No & 1.84 & $1.74-1.95$ & $<.001$ \\
\hline Yes & 1.41 & $1.22-1.61$ & \\
\hline \multicolumn{4}{|c|}{ Bronchopulmonary dysplasia } \\
\hline No & 1.89 & $1.75-2.02$ & .008 \\
\hline Yes & 1.63 & $1.49-1.76$ & \\
\hline \multicolumn{4}{|l|}{ Sepsis/NEC } \\
\hline No & 1.82 & $1.71-1.93$ & .016 \\
\hline Yes & 1.55 & $1.36-1.74$ & \\
\hline \multicolumn{4}{|l|}{ Vermis height } \\
\hline \multicolumn{4}{|l|}{ Postnatal corticosteroids } \\
\hline No & 0.63 & $0.58-0.69$ & .011 \\
\hline Yes & 0.49 & $0.39-0.59$ & \\
\hline \multicolumn{4}{|l|}{ Ventricular width } \\
\hline \multicolumn{4}{|l|}{ GA } \\
\hline$<28$ weeks & 0.64 & $0.57-0.71$ & .004 \\
\hline$\geq 28$ weeks & 0.41 & $0.27-0.55$ & \\
\hline
\end{tabular}

${ }^{a}$ Adjusted for gestational age, birth weight $z$ score, and sex.

${ }^{\mathrm{b}} \mathrm{P}$ value for the interaction between the perinatal variable and postnatal age.

roid exposure and slower TCD growth reported here is novel and needs to be replicated in future studies.

Liao et $\mathrm{al}^{33}$ and Levene ${ }^{34}$ reported serial measurements of the ventricular index in preterm infants from birth to 6 weeks' and 6 months' PNA, respectively, and found rates of change like those in the current study for the ventricular width (the sum of left and right ventricular indices). We found that lower GA was related to a faster rate of change in the ventricular width, possibly resulting from a greater burden of diffuse cerebral white matter injury in the less mature infants leading to greater ex vacuo dilation. Rates of change for the AHW with respect to PNA were variable and increased little after the first postnatal week, as also reported in other studies. ${ }^{33-36}$

A major strength of the current study is its use of simple and reproducible linear measures obtained from standard cUS performed as part of routine clinical care. We use the mastoid fontanel for cerebellar imaging and TCD measurement, a reliable approach that is not technically difficult. ${ }^{37}$ Our study, however, has several limitations. We used routine clinical scans timed to detect major preterm brain injury. There is, therefore, an inherent bias in our study cohort because the smaller, less mature infants were more likely to have had a greater burden of brain injury and, subsequently, a greater number of scans for monitoring the progression of any overt findings. It is also likely that these infants had more comorbidities and longer periods of hospitalization. In our neonatal unit, infants who no longer need tertiary-level care are transferred to nontertiary hospitals from as early as 32 weeks' PMA. The more mature infants in our cohort, unless they were very sick, were likely to have had fewer scans, limited to the early days and weeks after birth. However, the mixedeffects model used allows for different infants having different numbers of scans.

The cohort used in the current study will have developmental assessments throughout childhood, which will allow the relationships between sequential cUS linear measures of early postnatal brain growth and neurodevelopment in later childhood to be determined in the future.

\section{CONCLUSIONS}

Brain growth in infants born at $<30$ weeks' GA can be assessed using simple and reproducible linear measures made on sequential cUS. Several perinatal variables already shown to be related to long-term development, including GA, BW $z$ score, bronchopulmonary dysplasia, postnatal corticosteroids, and sepsis and/or NEC, were associated with early postnatal brain growth. Further research is needed to evaluate the usefulness of brain growth, as evaluated using sequential cUS linear measures, as a marker of long-term neuro developmental outcome.

\section{ACKNOWLEDGMENTS}

We acknowledge Merilyn Bear, Emma McInnes, Brenda Argus, Bernice Mills, and Nicole van der Linden for their input into recruitment of infants and their families for this study.

Disclosures: Rocco Cuzzilla—UNRELATED: Employment: The Royal Women's Hospital, Melbourne, Comments: This is my clinical employer. Alicia J. Spittle-RELATED: Grant: National Health and Medical Research Council, Comments: Career Development Fellowship ID 1108714. Katherine J. Lee-RELATED: Grant: National Health Medical Research Council, Comments: Career Development Fellowship ID 1127984. Sheryle Rogerson-UNRELATED: Payment for Lectures Including Service on Speakers Bureaus: GE Webinar lectures, Comments: paid for 1 webinar lecture on cranial ultrasound (November 2016). Frances M. Cowan-UNRELATED: Employment: Chelsea and Westminster Hospital, Comments: teaching and reviewing neonatal brain imaging; Payment for Lectures Including Service on Speakers Bureaus: Imperial College London Symposium, Comments: remuneration for teaching a 3-day course on cranial ultrasound. Lex W. Doyle-RELATED: Grant: National Health and Medical Research Council of Australia, Comments: Centre of Research Excellence grant.* Jeanie L.Y. Cheong-RELATED: Grant: National Health and Medical Research Coun- 
cil, Comments: Career Development Fellowship ID 1141354; UNRELATED: Employment: The Royal Women's Hospital, Melbourne, Comments: This is my clinical employer. *Money paid to the institution.

\section{REFERENCES}

1. Woodward LJ, Anderson PJ, Austin NC, et al. Neonatal MRI to predict neurodevelopmental outcomes in preterm infants. $N$ Engl J Med 2006;355:685-94 CrossRef Medline

2. De Vries LS, Van Haastert IL, Rademaker KJ, et al. Ultrasound abnormalities preceding cerebral palsy in high-risk preterm infants. J Pediatr 2004;144:815-20 Medline

3. Plaisier A, Raets MM, Ecury-Goossen GM, et al. Serial cranial ultrasonography or early MRI for detecting preterm brain injury? Arch Dis Child Fetal Neonatal Ed 2015;100:F293-300 CrossRef Medline

4. Leijser LM, de Bruïne FT, van der Grond J, et al. Is sequential cranial ultrasound reliable for detection of white matter injury in very preterm infants? Neuroradiology 2010;52:397-406 CrossRef Medline

5. Miller SP, Cozzio CC, Goldstein RB, et al. Comparing the diagnosis of white matter injury in premature newborns with serial MR imaging and transfontanel ultrasonography findings. AJNR Am J Neuroradiol 2003;24:1661-69 Medline

6. Laptook AR, O'Shea TM, Shankaran S, et al. Adverse neurodevelopmental outcomes among extremely low birth weight infants with a normal head ultrasound: prevalence and antecedents. Pediatrics 2005;115:673-80 CrossRef Medline

7. Ment LR, Bada HS, Barnes P, et al. Practice parameter: neuroimaging of the neonate: report of the Quality Standards Subcommittee of the American Academy of Neurology and the Practice Committee of the Child Neurology Society. Neurology 2002;58:1726-38 CrossRef Medline

8. Fox LM, Choo P, Rogerson SR, et al. The relationship between ventricular size at $\mathbf{1}$ month and outcome at 2 years in infants less than 30 weeks' gestation. Arch Dis Child Fetal Neonatal Ed 2014;99: F209-14 CrossRef Medline

9. Anderson NG, Laurent I, Woodward LJ, et al. Detection of impaired growth of the corpus callosum in premature infants. Pediatrics 2006;118:951-60 CrossRef Medline

10. Roelants, JA, Koning, IV, Raets MM, et al. A new ultrasound marker for bedside monitoring of preterm brain growth. AJNR Am J Neuroradiol 2016;37:1516-22 CrossRef Medline

11. Spittle AJ, Thompson DK, Brown NC, et al. Neurobehaviour between birth and 40 weeks' gestation in infants born $<30$ weeks' gestation and parental psychological wellbeing: predictors of brain development and child outcomes. BMC Pediatr 2014;14:111 CrossRef Medline

12. de Vries LS, Eken P, Dubowitz LM. The spectrum of leukomalacia using cranial ultrasound. Behav Brain Res 1992;49:1-6 CrossRef Medline

13. Papile LA, Burstein J, Burstein R, et al. Incidence and evolution of subependymal and intraventricular hemorrhage: a study of infants with birth weights less than 1,500 gm. J Pediatr 1978;92:529-34 CrossRef Medline

14. Doyle LW, Cheong JL, Burnett A, et al; Victorian Infant Collaborative Study Group. Biological and social influences on outcomes of extreme-preterm/low-birth weight adolescents. Pediatrics 2015;136: e1513-20 CrossRef Medline

15. Bell MJ, Ternberg JL, Feigin RD, et al. Neonatal necrotizing enterocolitis: therapeutic decisions based upon clinical staging. Ann Surg 1978;187:1-7 CrossRef Medline

16. Hagmann CF, Robertson NJ, Acolet D, et al. Cerebral measurements made using cranial ultrasound in term Ugandan newborns. Early Hum Dev 2011;87:341-47 CrossRef Medline

17. Anderson NG, Laurent I, Cook N, et al. Growth rate of corpus callosum in very premature infants. AJNR Am J Neuroradiol 2005;26: 2685-90 Medline
18. Williams J, Hirsch NJ, Corbet AJ, et al. Postnatal head shrinkage in small infants. Pediatrics 1977;59:619-22 Medline

19. Kurmanavicius J, Wright EM, Royston $\mathrm{P}$, et al. Fetal ultrasound biometry, 1: head reference values. Br J Obstet Gynaecol 1999;106: 126-35 CrossRef Medline

20. Bouyssi-Kobar M, du Plessis AJ, McCarter R, et al. Third trimester brain growth in preterm infants compared with in utero healthy fetuses. Pediatrics 2016;138. pii: e20161640 CrossRef Medline

21. Nguyen The Tich S, Anderson PJ, Shimony JS, et al. A novel quantitative simple brain metric using MR imaging for preterm infants. AJNR Am J Neuroradiol 2009;30:125-31 CrossRef Medline

22. Achiron R, Achiron, A. Development of the human fetal corpus callosum: a high-resolution, cross-sectional sonographic study. $U l$ trasound Obstet Gynecol 2001;18:343-47 CrossRef Medline

23. Malinger G, Zakut, H. The corpus callosum: normal fetal development as shown by transvaginal sonography. AJR Am J Roentgenol 1993;161:1041-43 CrossRef Medline

24. Imamoglu EY, Gursoy T, Ovali F, et al. Nomograms of cerebellar vermis height and transverse cerebellar diameter in appropriate-for-gestational-age neonates. Early Hum Dev 2013;89:919-23 CrossRef Medline

25. Chavez MR, Ananth CV, Smulian JC, et al. Fetal transcerebellar diameter measurement for prediction of gestational age at the extremes of fetal growth. J Ultrasound Med 2007;26:1167-71; quiz 1173-74 Medline

26. Chavez MR, Ananth CV, Kaminsky LM, et al. Fetal transcerebellar diameter measurement for prediction of gestational age in twins. Am J Obstet Gynecol 2006;195:1596-600 CrossRef Medline

27. Davies MW, Swaminathan M, Betheras FR. Measurement of the transverse cerebellar diameter in preterm neonates and its use in assessment of gestational age. Australas Radiol 2001;45:309-12 CrossRef Medline

28. Kyriakopoulou V, Vatansever D, Davidson A, et al. Normative biometry of the fetal brain using magnetic resonance imaging. Brain Struct Funct 2017;222:2295-307 CrossRef Medline

29. Zalel Y, Seidman DS, Brand N, et al. The development of the fetal vermis: an in-utero sonographic evaluation. Ultrasound Obstet Gynecol 2002;9:136-39 Medline

30. Tam EW, Chau V, Ferriero DM, et al. Preterm cerebellar growth impairment after postnatal exposure to glucocorticoids. Sci Transl Med 2011;3:105ra105 CrossRef Medline

31. Thompson DK, Inder TE, Faggian N, et al. Corpus callosum alterations in very preterm infants: perinatal correlates and 2 year neurodevelopmental outcomes. Neuroimage 2012;59:3571-81 CrossRef Medline

32. Shah DK, Doyle LW, Anderson PJ, et al. Adverse neurodevelopment in preterm infants with postnatal sepsis or necrotizing enterocolitis is mediated by white matter abnormalities on magnetic resonance imaging at term. J Pediatr 2008;153170-75, 175.e1 CrossRef Medline

33. Liao MF, Chaou WT, Tsao LY, et al. Ultrasound measurement of the ventricular size in newborn infants. Brain Dev 1986;8:262-68 CrossRef Medline

34. Levene MI. Measurement of the growth of the lateral ventricles in preterm infants with real-time ultrasound. Arch Dis Child 1981;56 900-04 CrossRef Medline

35. Sondhi V, Gupta G, Gupta PK, et al. Establishment of nomograms and reference ranges for intra-cranial ventricular dimensions and ventriculo-hemispheric ratio in newborns by ultrasonography. Acta Paediatr 2008;97:738-44 CrossRef Medline

36. Perry RN, Bowman ED, Murton LJ, et al. Ventricular size in newborn infants. J Ultrasound Med 1985;4:475-77 CrossRef Medline

37. da Graca AL, Cardoso KR, da Costa JM, et al. Assessment of gestational age using cerebellar measurements at cranial ultrasound: what is the best approach? Early Hum Dev 2013;89:1-5 CrossRef Medline 